\title{
A Study of Depression among Caregivers of Individuals with Intellectual Disability - A cross sectional study
}

\author{
Pradeep Shankarrao Bodke ${ }^{1}$, Umesh Bapuji Atram ${ }^{2}$, Sainath Lachmanna Maidapwad ${ }^{3}$ \\ ${ }^{1}$ Associate Professor, Department of Psychiatry \\ ${ }^{2}$ Assistant Professor, Department of Psychiatry \\ ${ }^{3}$ Assistant Professor \& Statistician, Department of Community Medicine, \\ Dr. Shankarrao Chavan Government Medical College, Nanded.
}

Corresponding author: Umesh Atram

Email - umeshatram245@gmail.com

\begin{abstract}
Background and Objectives: Caregivers of children with intellectually disability experiences high level of emotional, financial and physical stress. The aim of this study is to assess the risk of depression among caregivers of individuals with intellectually disability.

Methods: A cross sectional study was done on caregivers of intellectually disabled individuals who has attended Psychiatry outpatient, Department of Government Medical College. 60 patients diagnosed with ID were included by systematic random sampling method. Objective data was collected in a special proforma. Patient health questionnaire (PHQ-9) was used to assess risk of depression among caregivers of Individuals with Intellectually Disabled. MS Excel sheet and SPSS were used for data entering and statistical analysis.

Results: On PHQ-9 scale, $71.7 \%$ of caregivers had depression out of which, $26.6 \%$ shows minimal symptoms of depression, $20 \%$ had mild depression, while $13.4 \%$ had moderately severe depression and 11.6 $\%$ had major severe depression while $28.3 \%$ of caregivers had no depression. Depression was more common in females $(36.6 \%)$ than males $(35 \%)$.

Conclusion: The prevalence of depression among caregivers of Individual with intellectually disabled was higher in this study. The risk of depression was higher in female caregivers as compared to male caregivers.
\end{abstract}

Keywords: Depression, caregivers, intellectual disability, mental retardation.

(Paper received $-9^{\text {th }}$ November 2018 , Peer review completed $-29^{\text {th }}$ November 2018$)$

(Accepted $-3^{\text {rd }}$ December 2018)

\section{INTRODUCTION}

Intellectual disability is a disability that occurs before age 18. People with this disability experience significant limitations in two main areas: intellectual functioning and adaptive behaviour. These limitations are expressed in person's conceptual, social and practical everyday living skills [1]. According to ICD-10, Intellectual disability can be classified into four classes on the basis of intelligent quotient (IQ) i.e. mild IQ 50-70, moderate IQ 35-50, severe IQ 20-35, profound IQ below 20. A number of people with intellectual disability are mildly affected, making the disability difficult to recognize without visual cues. In intellectual disability there is a significantly sub-average mental development from birth or early childhood. It is substantial limitations in age appropriate intellectual functioning and adaptive behaviour and it is a lifelong condition. These children are slow in reaching developmental milestones later than the normal children. Intellectual disability affects about $2-3 \%$ of people, $75-90 \%$ of the affected people have an intellectual 
disability [2]. In intellectual disability there is marked impairment in communication, academic and social skills due to which the child is more dependent on care giver than normal child. The parents of children with intellectual disabilities experience chronic stress. It is also seen that having a child with intellectual disabilities affects not only the parents, but also siblings and the relationships among the family members [3]. Stress experienced by the caregivers of disabled child is influenced by several factors such as child's age, gender, degree of disability and also social class, economic status and family coping strategies like acceptance of the child's diagnosis and perception of stigma associated with the disorder [4]. Becoming a caregiver of disabled child introduces an additional role, and therefore will require some rearrangement of priorities, and redirection of energy [5]. Therefore, the caregiver should monitor changes in person's mental condition, including becoming unhappy, depressed, confused, or otherwise not as healthy as they have been. In all this monitoring it is caregiver's duty to inform to doctor if anything unusual happens [6]. Various studies across the globe have already focused on the relation between evidence of psychological distress in caregivers of disabled children [7-9]. A study done in Kenya on caregivers of children with intellectual disability shows that majority (79\%) of caregivers were at risk of depression [10]. Freidrich et al studied the sample of 112 mothers of intellectual disabilities with developmental delay had noticed that depression among mothers had been increased from time one to two [11]. However, there is little data in developing countries like India on this topic [12]. Therefore, the aim of this study is to assess prevalence of depression in caregivers of ID children, to study clinical profile of ID, and the relation between demographic variables and depression in the caregivers of the intellectually disabled children.

\section{METHODOLOGY}

This cross-sectional study was conducted at department of psychiatry of Dr Shankarrao Chavan Government Medical college Nanded which is located in eastern Maharashtra. Caregivers of the persons with intellectually disabled attended out-patient department of psychiatry for either certification or treatment of behavioural problems who met inclusion criteria were screened. Patients of any age, diagnosed intellectually disabled according to DSM-5 and whose caregivers willing to sign an informed consent were included in study. The caregivers who participated in the study were explained the nature of study and were assured of confidentiality.

A sample of 60 patients were selected for the study. The enrolled participants were subjected to a sociodemographic details to collect data on gender, age, family income, type of family, religion, residence, education and occupation. Patients who included in this study were subjected to IQ assessments by clinical psychologist.

\section{Inclusion Criteria}

$>$ Caregivers of more than 18 years of age who were willing to participate in the study

$>$ Caregivers of intellectually disabled patients

$>$ Confirmed diagnosis of ID according to DSM-5 criteria.

$>$ Both male and female caregivers were included in the study

\section{Exclusion Criteria}

$>$ Caregivers with preexisting psychiatric illness

$>$ History of sever medical or surgical illness

$>$ Caregivers who were not willing to participate

The caregivers were administered Patient Health Questionnaire (PHQ 9) [13]. PHQ 9 was used to determine depression status in caregivers. The PHQ 9 was designed for use in medical and clinical settings. PHQ9 uses a four-point Likert scale $(0=$ not at all, $1=$ several days, $2=$ more than half the days, $3=$ nearly every day $)$ to gauge responses to questions asking about the respondents emotional/mental health over the last 2 week period. It is suitable for use in screening for depression among parents of children with severe disabilities [14]. 
Scores on the PHQ 9 can range from 0-27; scores between 0 and 4 indicate no depression, 5-9 indicate minimal symptoms, 10-14 indicate mild depression, 15-19 indicate moderately severe depression, and score $\geq 20$ indicate severe depression [13]. Reliability and validity studies of PHQ9 indicate that PHQ9 has sound psychometric properties it has high internal consistency. Study of two different patient populations and 6000 participations has shown Cronbach's alpha of 0.86 and 0.89 . Test-retest reliability of PHQ9 has high correlation at $\mathrm{r}=0.84$, discriminant validity of $\mathrm{PHQ} 9$ was established by ROC analysis that produced an area under the curve of 0.95 when diagnosing depression [13]. It has high sensitivity and specificity [13]. Since Marathi version of the original Patient health questionnaire was not available. It was translated in Marathi language. The selection of questions was done from the translated version. It was translated in such a way that the meaning of translated question should be same as the meaning of the questions in English. The selected words for framing questions were very familiar to Marathi language. It was again translated back to English to compare the original. Translations were done by doctor who were bilingual. The data collected was tabulated in an excel spreadsheet and subjected to statistical analysis.

\section{RESULTS}

In this study, 60 intellectually disabled children and their care givers were included. Considering sociodemographic variables of intellectually disabled children, $51.7 \%$ were males and $48.3 \%$ females. Most of the children in this study belonged to the age group of $1-18$ years $(51.7 \%)$ and $71.1 \%$ were from nuclear family and $28.3 \%$ from joint family background. Seventy percent of the children were from rural area and $76.7 \%$ children were Hindu followed by $20 \%$ Muslim by religion. Sixteen percent children had mild ID, $41 \%$ moderate ID, $36 \%$ severe ID, $5 \%$ had profound ID. (Table 1 )

Table 1: Association between Socio-demographic characteristic factors of patients and degree of disability of patients

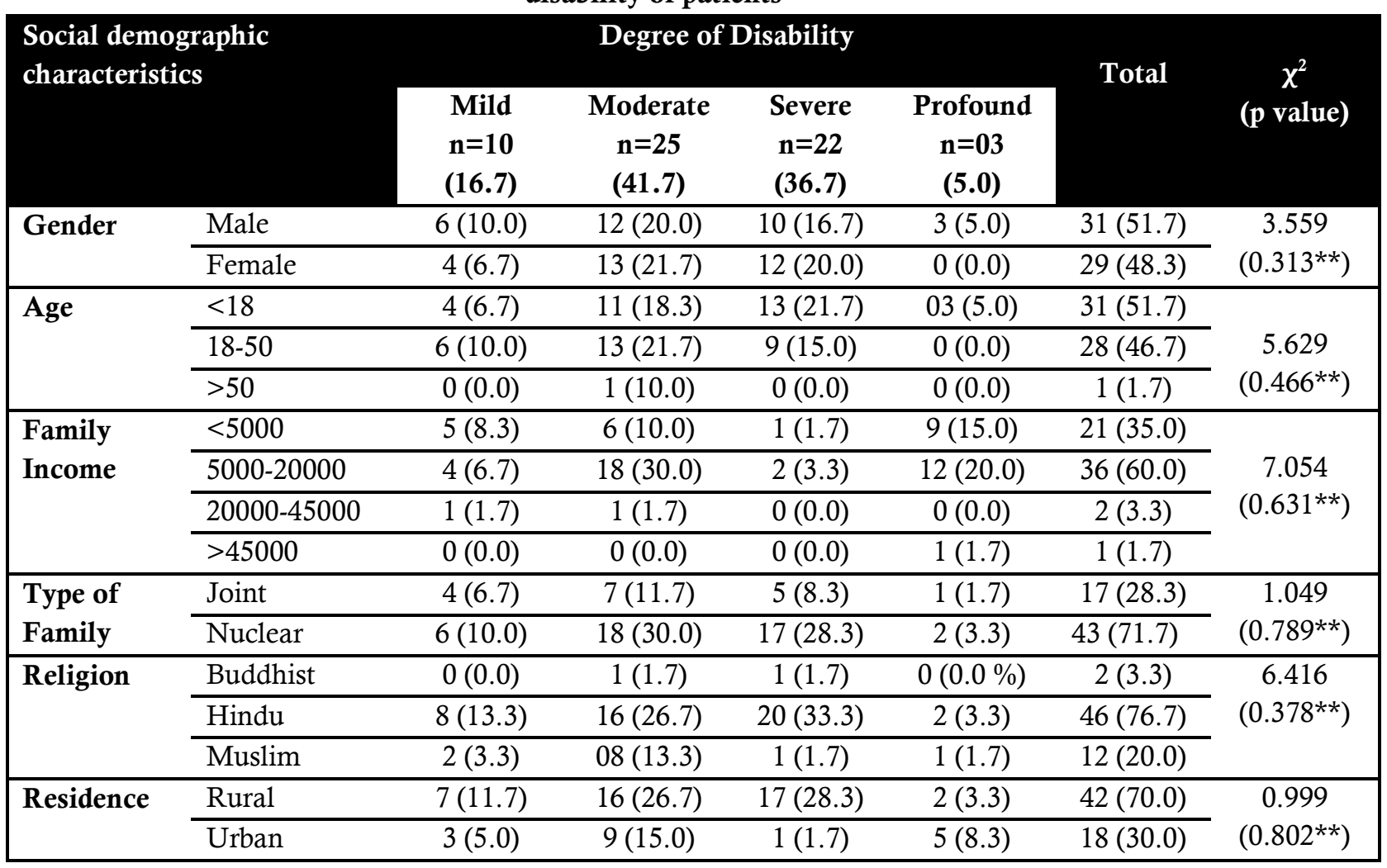

In our study, most of the caregivers were males (53.3\%) than females (46.7\%). Seventy percent caregivers were in 26-50 years age group followed by twenty one percent from more than 50 years. Considering family background of caregivers, the majority of caregivers were from nuclear family $(71.7 \%)$ background and the families whose earning capacities was in between 5000-20000/month were $60 \%$, while $35 \%$ families had 
less than 5000/ month income. Moreover, caregivers from rural background (70\%) form the major group than urban background (30\%). On religion basis, $76.7 \%$ of caregivers were Hindu by religion (Table 2).

Table 2: Association between Social demographic factors of caregivers and degree of depression

\begin{tabular}{|c|c|c|c|c|c|c|c|c|}
\hline \multirow{2}{*}{\multicolumn{2}{|c|}{$\begin{array}{l}\text { Socio-demographic } \\
\text { characteristics }\end{array}$}} & \multicolumn{5}{|c|}{ Degree of Depression } & \multirow{2}{*}{ Total } & \\
\hline & & No & Minimal & Mild & Moderately & Majo & & \\
\hline \multirow[t]{2}{*}{ Gender } & Male & $11(18.3)$ & $8(13.3)$ & $7(11.7)$ & $4(6.7)$ & $2(3.3)$ & $32(53.3)$ & \multirow{2}{*}{$\begin{array}{c}2.836 \\
\left(0.587^{* *}\right)\end{array}$} \\
\hline & Female & $6(10)$ & $8(13.3)$ & $5(8.3)$ & $4(6.7)$ & $5(8.3)$ & $28(46.7)$ & \\
\hline \multirow[t]{3}{*}{ Age } & $\leq 25$ & $1(1.7)$ & $2(3.3)$ & $0(0.0)$ & $0(0.0)$ & $1(1.7)$ & $4(6.7)$ & \multirow{3}{*}{$\begin{array}{c}9.869 \\
\left(0.274^{* *}\right)\end{array}$} \\
\hline & $26-50$ & $15(25.0)$ & $9(15.0)$ & $7(11.7)$ & $7(11.7)$ & $5(8.3)$ & $43(71.7)$ & \\
\hline & $>50$ & $1(1.7)$ & $5(8.3)$ & $5(8.3)$ & $1(1.7)$ & $1(1.7)$ & $13(21.7)$ & \\
\hline \multirow{4}{*}{$\begin{array}{l}\text { Family } \\
\text { Income }\end{array}$} & $<5000$ & $5(8.3)$ & $6(10.0)$ & $3(5.0)$ & $4(6.7)$ & $3(5.0)$ & $21(35.0)$ & \multirow{4}{*}{$\begin{array}{c}6.397 \\
\left(0.895^{* *}\right)\end{array}$} \\
\hline & $5000-20000$ & $11(18.3)$ & $9(15.0)$ & $8(13.3)$ & $4(6.7)$ & $4(6.7)$ & $36(60.0)$ & \\
\hline & $20000-45000$ & $0(0.0)$ & $1(1.7)$ & $1(1.7)$ & $0(0.0)$ & $0(0.0)$ & $2(3.3)$ & \\
\hline & $>45000$ & $1(1.7)$ & $0(0.0)$ & $0(0.0)$ & $0(0.0)$ & $0(0.0)$ & $1(1.7)$ & \\
\hline \multirow{2}{*}{$\begin{array}{l}\text { Type of } \\
\text { Family }\end{array}$} & Joint & $5(8.3)$ & $7(11.7)$ & $1(1.7)$ & $1(1.7)$ & $3(5.0)$ & $17(28.3)$ & \multirow{2}{*}{$\begin{array}{c}5.961 \\
\left(0.202^{* *}\right)\end{array}$} \\
\hline & Nuclear & $12(20.0)$ & $9(15.0)$ & $11(18.3)$ & $7(11.7)$ & $4(6.7)$ & $43(71.7)$ & \\
\hline \multirow[t]{3}{*}{ Religion } & Buddhist & $0(0.0)$ & $1(1.7)$ & $1(1.7)$ & $0(0.0)$ & $0(0.0)$ & $2(3.3)$ & \multirow{3}{*}{$\begin{array}{c}9.557 \\
\left(0.297^{* *}\right)\end{array}$} \\
\hline & Hindu & $15(25.0)$ & $12(20.0)$ & $9(15.0)$ & $7(11.7)$ & $3(5.0)$ & $46(76.7)$ & \\
\hline & Muslim & $2(3.3)$ & $3(5.0)$ & $2(3.3)$ & $1(1.7)$ & $4(6.7)$ & $12(20.0)$ & \\
\hline \multirow[t]{2}{*}{ Residence } & Rural & $12(20.0)$ & $11(18.3)$ & $8(13.3)$ & $8(13.3)$ & $3(5.0)$ & $42(70.0)$ & \multirow{2}{*}{$\begin{array}{c}5.963 \\
\left(0.202^{* *}\right)\end{array}$} \\
\hline & Urban & $5(8.3)$ & $5(8.3)$ & $4(6.7)$ & $0(0.0)$ & $4(6.7)$ & $18(30.0)$ & \\
\hline
\end{tabular}

Majority of caregivers were illiterate (36.7\%), while $20 \%$ educated up to primary level, $16.7 \%$ studied up to SSC level. By occupation, forty one percent of caregivers were labour, $25 \%$ were farmer. (Table 3 )

On PHQ-9 scale, $71.7 \%$ of caregivers had depression out of which, $26.6 \%$ shows minimal symptoms of depression, $20 \%$ had mild depression, while $13.4 \%$ had moderately severe depression and $11.6 \%$ had major severe depression while $28.3 \%$ of caregivers had no depression. Depression was more common in females (36.6\%) than males (35\%) in our study. Caregivers whose age in between 26- 50 years experienced more depressive features $(46.7 \%)$ than other age groups. Depression found more in caregivers whose family income in between 5000-20000/month (41.7\%). Caregivers from nuclear families $(51.7 \%)$ had more depression than joint families $(20 \%)$.

A significant association was found between caregiver's depression and degree of intellectual disability of their children $(p$ value $=0.044$ ). The depression was highest among caregivers of children with moderate disability (41.7\%) followed by severe disability (36.7\%). (Table.4) A significant association was found between associated disability of ID Individuals and caregivers depression $(p=0.14)$.

\section{DISCUSSION}

The study was carried out in the out-patient Department of Psychiatry, Dr S.C. Govt. Medical College and hospital. Caregivers, who come to psychiatry department for certification or treatment for behavioural problems of their intellectually disabled child, were recruited after informed consent. In our study, 60 intellectually disabled children and their care givers were included. Among intellectually disabled children majority were males. Sixteen percent children had mild ID, $41 \%$ moderate ID, $36 \%$ severe ID, $5 \%$ had profound ID. Most of the intellectually disabled children were deprived of schooling because of degree of disability they had. 
Table 3: Association between education and occupation of caregivers and degree of depression

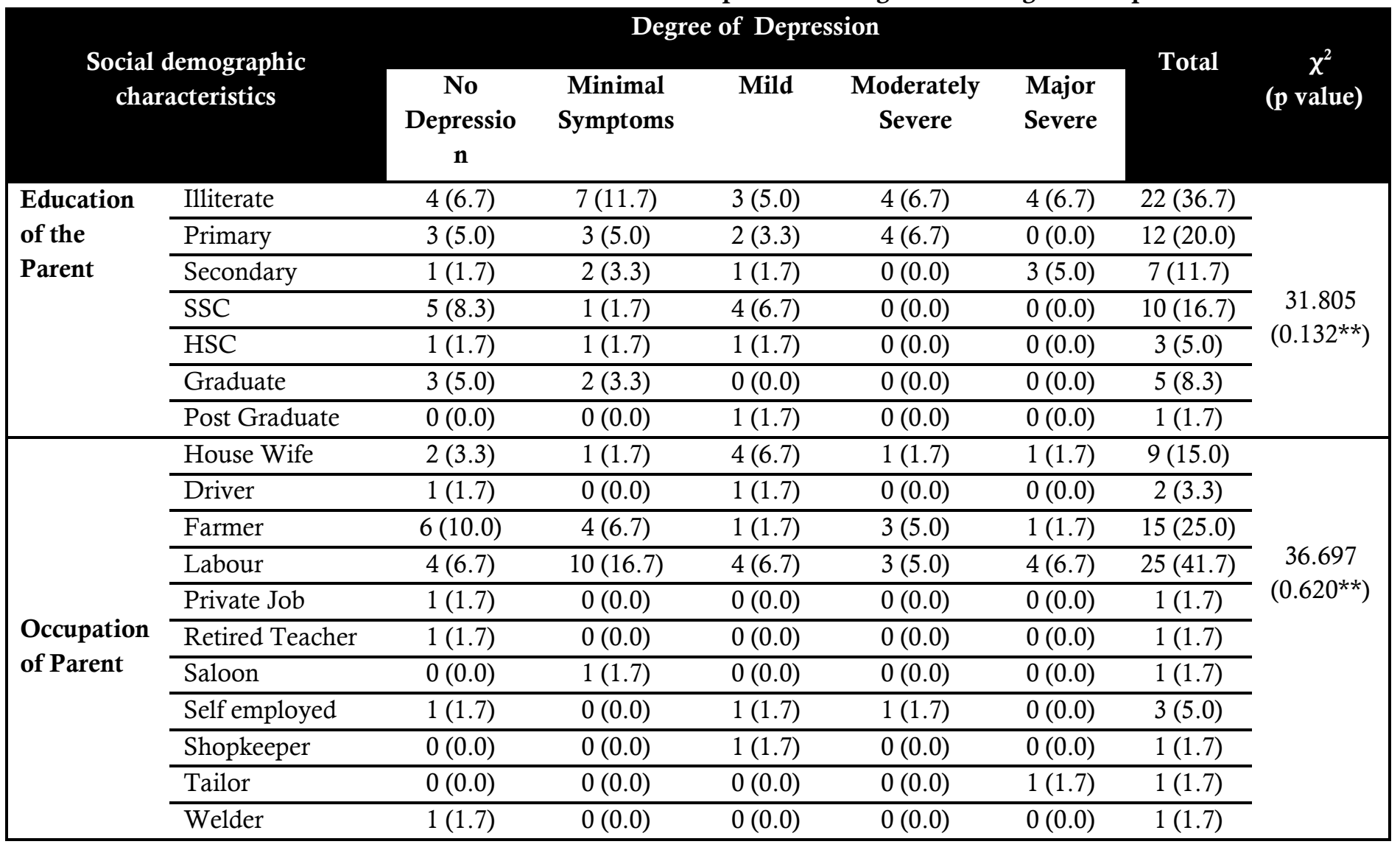

Table 4: Association between Degree of Severity of ID and Depression

\begin{tabular}{|c|c|c|c|c|c|c|}
\hline \multirow[t]{2}{*}{ PHQ-9 Score } & \multicolumn{4}{|c|}{ Degree of Disability } & \multirow[t]{2}{*}{ Total } & \multirow{2}{*}{$\begin{array}{c}\chi^{2} \\
\text { (p value) }\end{array}$} \\
\hline & Mild & Moderate & Severe & Profound & & \\
\hline $\begin{array}{l}\text { No Depression } \\
(<5)\end{array}$ & $\begin{array}{c}3 \\
(5.0 \%)\end{array}$ & $\begin{array}{c}6 \\
(10.0 \%)\end{array}$ & $\begin{array}{c}7 \\
(11.7 \%)\end{array}$ & $\begin{array}{c}1 \\
(1.7 \%)\end{array}$ & $\begin{array}{c}17 \\
(28.3 \%)\end{array}$ & \\
\hline $\begin{array}{l}\text { Minimal Symptoms } \\
(5-9)\end{array}$ & $\begin{array}{c}2 \\
(3.3 \%)\end{array}$ & $\begin{array}{c}7 \\
(11.7 \%)\end{array}$ & $\begin{array}{c}7 \\
(11.7 \%)\end{array}$ & $\begin{array}{c}0 \\
(0.0 \%)\end{array}$ & $\begin{array}{c}16 \\
(26.7 \%)\end{array}$ & \\
\hline $\begin{array}{l}\text { Minor Depression, Mild } \\
(10-14)\end{array}$ & $\begin{array}{c}5 \\
(8.3 \%) \\
\end{array}$ & $\begin{array}{c}5 \\
(8.3 \%) \\
\end{array}$ & $\begin{array}{c}2 \\
(3.3 \%) \\
\end{array}$ & $\begin{array}{c}0 \\
(0.0 \%) \\
\end{array}$ & $\begin{array}{c}12 \\
(20.0 \%) \\
\end{array}$ & \\
\hline $\begin{array}{l}\text { Major Depression, } \\
\text { Moderately Severe } \\
(15-19)\end{array}$ & $\begin{array}{c}0 \\
(0.0 \%)\end{array}$ & $\begin{array}{c}3 \\
(5.0 \%)\end{array}$ & $\begin{array}{c}5 \\
(8.3 \%)\end{array}$ & $\begin{array}{c}0 \\
(0.0 \%)\end{array}$ & $\begin{array}{c}8 \\
(13.3 \%)\end{array}$ & $\begin{array}{c}21.434 \\
\left(p=0.044^{*}\right)\end{array}$ \\
\hline $\begin{array}{l}\text { Major Depression, Severe } \\
(>20)\end{array}$ & $\begin{array}{c}0 \\
(0.0 \%)\end{array}$ & $\begin{array}{c}4 \\
(6.7 \%)\end{array}$ & $\begin{array}{c}1 \\
(1.7 \%)\end{array}$ & $\begin{array}{c}2 \\
(3.3 \%)\end{array}$ & $\begin{array}{c}7 \\
(11.7 \%)\end{array}$ & \\
\hline Total & $\begin{array}{c}10 \\
(16.7 \%)\end{array}$ & $\begin{array}{c}25 \\
(41.7 \%)\end{array}$ & $\begin{array}{c}22 \\
(36.7 \%)\end{array}$ & $\begin{array}{c}3 \\
(5.0 \%)\end{array}$ & $\begin{array}{c}60 \\
(100 \%)\end{array}$ & \\
\hline
\end{tabular}

Most of the caregivers were unaware of the educational facilities available for their children and this could be another reason due to which these children are deprived of schooling. Hence every mental health professional should make them aware about facilities like special education in special schools.

In our study, $71.7 \%$ of caregivers of intellectually disabled children were at risk of depression as derived from PHQ9 score, this finding is consistent with other studies [10-11, 15-16]. In one study [16], 85\% of the mothers of the mentally retarded suffer from depression. Moreover, Solomon study noted $72.1 \%$ of caregivers of were at risk of depression [17]. The depression seen in Indian studies is more than the studies done around the world15. Having a child with intellectual disability, a family faces many challenges such as psychological 
distress, interactive family issues, disturbed schedules and additional expenses, which can create financial burden on family and there requires a reorientation and re-evaluation of family goals, responsibilities and relationships [18-20]. Those caregivers of ID children who were diagnosed as having depression they needed mental health services and support. Finding predicting factors of depression among caregivers of intellectually disabled child may help in identifying those caregivers who need special care by mental health professional to reduce their risk of psychological distress.

In our study sample, depression was more common in female caregivers $(36.6 \% 0)$ than male caregivers. This finding is in consistent with previous studies $[10,20]$. As in Indian culture the female have high social responsibilities and they are the primary care takers of their children. Within that context, in nuclear families, stress and care demands are expected to be strongest for females [20-21]. Accordingly, females are more vulnerable to the psychological distress associated with child's behavioural problems [22]. Researchers have noticed [23] that $22 \%$ of female visited doctor concerning about their psychological problems are due to their children. From the observations and results it can be concluded that, there is direct correlation between degrees of disability in intellectually disabled child with level of depression in caregivers. The levels of depression were more in caregivers whose ID child had moderate to severe disability. This was statistically found significant. Similar findings have been shown in previous studies [20,24]. As the severity of disability in ID child increases, the child may face impairments in different areas of adaptive functioning like self-care, academic, home living, use of community resources etc. and within that context, the more special care requires from caregivers that leads to additional burden on caregivers which may result in psychological distress.

In our study, the maximum number of caregivers is from the age group of 26-50 years. This finding is in consistent with a study [24] in which they found maximum number of caregivers were from the age group of 36-50 years. In our study this age group had more risk of depression than other age group. This may be due to, the caregivers in younger age group could have more worries about their intellectually disabled child's future and this may predispose them to depression. From observations it can be concluded that, caregivers from nuclear family background had higher levels of risk of depression as compared to caregivers from joint family background. In joint family there are other family members who can help to take care of ID child but in nuclear family the burden of care of ID child remain on alone which may attribute to psychological distress among caregivers from nuclear family background. Moreover, the risk of depression was higher among the illiterate and primarily educated caregivers from the study sample.

\section{Limitations}

- $\quad$ Small sample size

- This study is hospital based conducted in single locality, so that bias may have occurred in selection of sample population hence, it would be difficult to ascertain if the risk of depression of caregivers would be the same or different from other localities.

\section{CONCLUSION}

The prevalence of depression among caregivers of children with intellectually disabled was higher in this study. The risk of depression was higher in female caregivers as compared to male caregivers. Therefore, there is need to develop support system to prevent the risk of depression in the caregivers of intellectually disabled children.

\section{REFERENCES}

1. Schalock RL, Borthwick-Duffy SA, Bradley VJ, Buntinx WH, Coulter DL, Craig EM, Gomez SC, Lachapelle Y, Luckasson R, Reeve A, Shogren KA. Intellectual disability: Definition, classification, and systems of supports. American Association on Intellectual and Developmental Disabilities. 444 North Capitol Street NW Suite 846, Washington, DC 20001; 2010.

2. Kalgotra R, Warwal JS. Intellectual Disability in India: An overview. J Disabil Stud 2017;3(1):18-30.

3. Rivers JW, Stoneman Z. Sibling relationships when a child has autism: Marital stress and support coping. J Autism Dev Disord 2003;33(4):383-94.

4. Beresford BA. Resources and strategies: How parents cope with the care of a disabled child. J Child Psychol Psychiatry 1994;35(1):171-209. 
5. Raina P, O'Donnell M, Rosenbaum P, Brehaut J, Walter SD, Russell D, Swinton M, Zhu B, Wood E. The health and well-being of caregivers of children with cerebral palsy. Pediatrics 2005;115(6):e626-36.

6. Nuba H, Searson M, Sheiman DL. Children's Literature: Developing Good Readers. Routledge; 2013.

7. Cramm JM, Nieboer AP. Psychological well-being of caregivers of children with intellectual disabilities: Using parental stress as a mediating factor. J Intellect Disabil 2011;15(2):101-13.

8. Khamis V. Psychological distress among parents of children with mental retardation in the United Arab Emirates. Soc Sci Med 2007;64(4):850-7.

9. Saloviita T, Itälinna M, Leinonen E. Explaining the parental stress of fathers and mothers caring for a child with intellectual disability: A double ABCX model. J Intellect Disabil Res 2003;47(4- 5):300-12.

10. Mbugua MN, Kuria MW, Ndetei DM. The prevalence of depression among family caregivers of children with intellectual disability in a rural setting in Kenya. Int J Fam Med 2011;2011.

11. Friedrich WN, Wilturner LT, Cohen DS. Coping resources and parenting mentally retarded children. Am J Mental Def 1985;2:11-6,

12. Dave D, Mittal S, Tiwari D, Parmar MC, Gedan S, Patel V. Study of anxiety and depression in caregivers of intellectually disabled children. J Res Med Dent Sci 2014;2(1):8-13.

13. Kroenke K, Spitzer RL, Williams JB. The PHQ- 9: validity of a brief depression severity measure. J Gen Intern Med 2001;16(9):606-13.

14. Blucker RT, Elliott TR, Warren RH, Warren AM. Psychological adjustment of family caregivers of children who have severe neurodisabilities that require chronic respiratory management. Fam Syst Health 2011;29(3):215-9.

15. Chandravanshi G, Sharma KK, Jilowa CS, Meena PS, Jain M, Prakash O. Prevalence of depression in mothers of intellectually disabled children: A cross-sectional study. Med J DY Patil Univ 2017;10(2):156-62.

16. Nagarkar A, Sharma JP, Tandon SK, Goutam P. The clinical profile of mentally retarded children in India and prevalence of depression in mothers of the mentally retarded. Indian J Psychiatry 2014;56(2):165-9.

17. Solomon MD. A study on depression, anxiety and stress among the parents of differently able children. Int $J$ Rec Innov Trends Comp Commun 2015;3(2):476-80.

18. Gohel M, Mukherjee S, Choudhary SK. Psychosocial impact on the parents of mentally retarded children in Anand District. Healthline 2011;2(2):62.

19. Kermanshahi SM, Vanaki Z, Ahmadi F, Kazemnejad A, Mordoch E, Azadfalah P. Iranian mothers' perceptions of their lives with children with mental retardation: A preliminary phenomenological investigation. J Dev Physical Disabil 2008;20(4):317-26.

20. Azeem MW, Dogar IA, Shah S, Cheema MA, Asmat A, Akbar M, Kousar S, Haider II. Anxiety and depression among parents of children with intellectual disability in Pakistan. J Can Acad Child Adolesc Psychiatry 2013;22(4):290-8.

21. Lamb ME, editor. The father's role: Applied perspectives. Wiley-Interscience; 1986.

22. Floyd FJ, Zmich DE. Marriage and the parenting partnership: Perceptions and interactions of parents with mentally retarded and typically developing children. Child Dev 1991;62(6):1434-48.

23. Emerson E, Robertson J, Wood J. Levels of psychological distress experienced by family carers of children and adolescents with intellectual disabilities in an urban conurbation. J Appl Res Intellect Disabil 2004;17(2):77-84.

24. Kumar I, Akhtar S. Rate of anxiety in mothers of mentally retarded children. Indian J Psychiatry 2001;43(2):27-32.

$$
\begin{gathered}
* * * * * * * * * * * * * * * * * * * * * * * * * * * * * * * * * * * * \\
\text { Acknowledgements }-\mathrm{Nil} \\
\text { Conflict of Interest }-\mathrm{Nil} \\
\text { Funding - Nil }
\end{gathered}
$$

